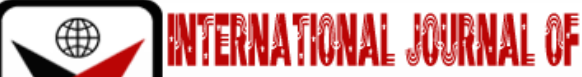

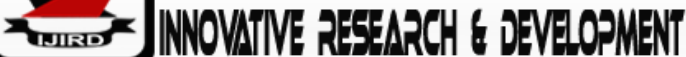

ISSN 2278-0211 (Online)

\section{Functional Analysis of Appelations among the Tongu-Ewe of the Volta Region of Ghana:The Case of Agave Traditional Area}

\author{
Clever Susuawu \\ Tutor, Department of Languages, Peki College of Education, Ghana
}

\begin{abstract}
:
The main purpose of this study is to do a functional analysis of appellations among the Ewe of Ghana: a case study of Agave Traditional Area among the Tongu-Ewe of the Volta Region of Ghana. The researcher interviewed family heads, clan heads and elders who have in-depth knowledge of appellation among the Tongus (Agave Traditional area regarding the various thematic areas of appellations. The study discusses the concepts and the genre to show that its aspects such as themes for example, evoke qualities cherished and enjoyed by the Tongu-Ewe. The study further analyses the structure of some selected appellations emphasizing the stem, justification or explanation of the stem and meanings which show that the structural elements contribute towards the creation of acceptable values and pleasure. It reinforces these notions by further analyzing and establishing the various situations embedded in the usage of the genre. The significance of appellations as sources of knowledge, wisdom, art, status-indexing, entertainment and moral education through social interaction and performance has been highlight. It was discovered that the rendering of appellation is seen as a process of socialization. The process explains the social structure and roles of individuals and their sense of communality and individuality. It has also been noticed that appellations make the members of the community cherish the beauty and usefulness of we-feeling, freedom of expression and independence. The study finally concludes that despite social change, the genre can survive and be sustained through education, adaptation, adjustment, theatre arts and the people's sense of creativity.
\end{abstract}

Keywords: Horn, functional, performance; devices, appreciation, transmission

\section{Introduction}

Appellations are sources of pleasure and satisfaction because they are sublime, beautiful and useful. They stimulate and soothe people, teach, encourage people for strenuous work and invigorate people's spirits. Appellations help in the renewal of people's spirits, executing, giving courage and enthusiasm to people for strenuous work. They help create a social bond between individuals and groups by arousing sympathy, understanding and the desire for harmonious relationships. The aesthetic experiences that are demonstrated through moods and attitudes can be thus summed up in one word, beauty. Every artistic work has beauty inextricably attached to it.

Appellations and their use among the Tongu-Ewe have direct moral implications. Appellations among the TonguEwe similarly evoke such moods and attitudes through the senses described by Mead. The people react to appellations in several ways through the sense of touch, sight, hearing, 'taste, and 'smell'. Thy show different attitudes also through various reactions such as smile, laughing, dancing, embracing and getting excited when the genre is being recited. Similarly, they are moody, angry and unhappy and exercise their displeasure when they are confronted with delivery of appellations that impact on them negatively through the senses. In the same manner, the people listen, understand and interpret appellations in words and actions. The impressions appellations make on their perceptions demonstrate their desires to own or disown them.

Opoku (1978) supports this assertion that moral values of West African peoples have to a large extent rest on conscience or the faculty of recognizing the distinction between right and wrong with regard to a person's own conduct. Composition, ownership and expression of appellations are directly related to the individual's conscience. It is realized then that within the socio-linguistic context, aesthetic values, beauty morality, knowledge and wisdom are inherent elements of appellations. These inherent characteristics are expressed for pleasure, participation and value judgment of an audience. The fact is that the delivery of appellations is useless if it does not involve the community and individuals. The genre is thus the product of individual minds and the collective possession of the community.

Through the audience the meaning of the occasion is made relevant. With the danger of repeating ourselves, we would say that context/occasion responds to the when/where/why of a performance; the composition, the what; the audience, for whom and transmission, the how. But very crucial, is who will actualize these, thus, the performer. 
The study and appreciation of oral literature is more important than ever for understanding the complexity of human cognition. For many people around the world-particularly in areas where history and traditions are still conveyed more through speech than in writing-the transmission of oral literature from one generation to the next lies at the heart of culture and memory. Very often, local languages act as vehicles for the transmission of unique forms of cultural knowledge. Oral traditions that are encoded in these speech forms can become threatened when elders die or when livelihoods are disrupted. Such creative works of oral literature are increasingly endangered as globalization and rapid socio-economic change exert ever more complex pressures on smaller communities, often challenging traditional knowledge practices.

\section{Statement of the Problem}

There has been series of studies in the literature regarding appellations: however, this research is to do a functional analysis of appellations among the Ewe of Agave Traditional Area.

\section{Research Questions}

- What functions do appellations perform among the Ewe of Agave traditional Area?

- By what means are the functions of appellations realized?

\section{Purpose of the Study}

The purpose of this study is to do a functional analysis of appellations among the Ewe of Agave Traditional Area.

\section{Review of Related Literature}

Appellations reveal the use of various aesthetics devices. This is also true of most appellations among the Ewes. The tonal nature of Ewe is fully exploited for these verbal language situations.Egblewogbe (1977) observes that Ewe appellations have formal structural features. He points out that, structural features. He points out that, structurally, Ewe praise-names are full of texts which take the form of proverbial statements or tuisms, and that for purposes of address and deference, only a truncated form of the name is used; that the full text are reserved for leisure and ceremonial occasions.

Finnegan (1970) discusses the prosody, pitch, styles such as the use of alliteration and assonance in panegyrics. The rest of the literary elements discussed in her study are parallelism, repetition, idiophones, interjections, imagery, simile, and metaphor. The impact of the use of these literary features has been clearly spelt out in her discussions; they are meant to explain actions and qualities of people and at the same time the beauty and the value of the genre. Unfortunately, her discussions are only general and do not relate to specific genres in which the literary features are exposed.

Okpewho (1992) identifies the background, character and continuity of oral literature in Africa. He devotes an aspect to stylistic qualities found in most African oral literature. He discusses, among other things, repetition, parallelism, piling and association, digression, imagery and symbolism. Okpewho, like Finnegan, failed to present and analyse the aesthetics and values of individual oral art. This study focuses on the presentation and analysis of the aesthetics and values of several but single appellations.

\section{Methodology}

The researcher informed the clan leaders, family heads, and those who have in-depth knowledge in appellation that he needed to interview them about issues concerning appellation. The researcher met the various leaders and gave them the time schedule for the appellation. As tradition and custom demands, the researcher offered the required drinks to the various leaders and few members of the clan and family respectively. These clan heads, family heads and those who are knowledgeable in this field took the researcher through series of thematic appellations. The researcher was briefed on when and where these appellations are appropriately used. The respondents requested that the researcher provides the necessary appellation resources such as: water, cloth, calabash, drum, drink (akpeteshie, palm wine, and other traditional herbs to invoke the spirits of the ancestors for more appellations. The day was set for the performance and everything wentsuccessfully.

Most of the data were collected in natural encounters by participant observation.Few clan leaders gathered and the ceremony stated. The resource person in charge of appellation welcomes the members from the society and indicated to the gathering that appellation have different importance and various occasions where they usually take place. After briefing the gathering about the purpose of the gathering, the resource person started the appellation process. The researcher gave appellations based on the various Appellations Performed Orally through Dialogue and Appellations on the Drum and with the Horn. The various occasions by which appellations are performed orally were demonstrated. Similarly, the ceremonies that required the appellation of the Drum and with the Horn were also exemplified. The researcher took notes and recordings of ceremony. The ceremony lasted about two hours and the researcher expressed his satisfaction to the gathering and assured the resource persons that the information they have provided would be kept confidential.

\section{Discussions}

The word aesthetics comes from the Greek verb, aesthesis, meaning 'to sense or perceive' (Titus and Smith (1974 p.176). This means that aesthetic is an experience. This experience, according to the two scholars, is the result of perceptual experience which is mostly visual, auditory and related to issues.

The Tongu-Ewe holds similar views about beauty. They use words and expressions which are synonymous with beauty, for instance, such as 'nyo' (good), 'dzani' (beautiful), w4leke (do beauty or make beautiful. Others are 'dzetugbe' 
(to be beautiful) or dze 2eka (to be handsome). These words and expressions are used by the people to describe the physical beauty of things, humans, speeches, actions, conduct and the beauty of appellations. Some appellation statements have in them descriptions of beauty as seen in the following.

- Agbal8 nyo ma2e: 2evia 2e ku be ye2e sr4. One does not marry a woman because of her beautiful skin. The child marries death claiming he marries a wife. Qualitatively, the appellation means that the beautiful skin colour of a lady can be deceptive. The colour of her skin is no guarantee that she will make a good wife.

- @a nyuiemedea du o; 2a nyuie le taw9 gakedumedenu le hi7w9m. Beautiful hair goes to town not. Beautiful hair is on your head but the thing to be used to go to town, you are lacking. The actual meaning is that a beautiful hair is not sufficient to qualify one to get to town. One may have it alright; but the one needs money to be able to get to town.

Additionally, there are expressions used to designate social and moral approval or disapproval among the TonguEwe. Some examples are 'es4 'ku' (it measures to the eye) 'enya kp4' (it is of good looking or tasteful), 'es4 to' (it is pleasing to the ear); 'edza' (it is pure) and 'edzeani' (it is crystal clear or simply beautiful). On the contrary, disapproved behavior is described in various words and expressions as 'ukpenanu' (shameful act), 'nu gbegbl8' (bad or ugly act) and 'nuw4na la vlo' (a deplorable or disguising act).

A well-structured appellation which is vividly expressed by a reciter is generally reacted to as "wò ' $k 4$ dze 'unye' (I love your beautiful appellation or your beautiful appellation appeals to me). It is worth emphasizing that the word beauty is also synonymous with goodness. So that, for the researcher, what is beautiful is equally and naturally good.

However, the researcher's operational definition is that aesthetic reflects actions, reactions, moods, tonality, thoughts and symbols expressed in any form of style appropriate to provoke linguistic and cultural values for the enrichment of an audience and society. This definition implies that aesthetic is an experience in life of the Tongu-Ewe. This aesthetic experience emerges from psycho-motor and cognitive skills, psychology, fine and oral art forms and their collective impact on the people. The operational definition is even more relevant and workable because it captures all that are exhibited practically, linguistically, socially and morally in the ownership and usage of appellations as a social and cultural tool of communication and education in which the people take pleasure in the experience of beautiful things. It is also important to note that appellations as Tongu-Ewe's aesthetic experience is culturally organized into activities such as play, recreation, ritual and art.

Furthermore, this experience utilizes the skilled production of forms that are expressive of feelings and culturally meaningful. Above all, appellations as aesthetic experience fulfills a variety of social functions including communication status, facilitating economic processes, instilling rituals with meaningful feelings supporting the political system and teaching social values.

Appellations experience also deals with standards of values of human life. This means that value and judgment cannot be ignored when dealing with aesthetic experience and appellations. Gyekye (1996 p. 125) affirms that aesthetic is characterized by delight, interest and enjoyment experienced by humans in response to objects, events, thought of social advantage, economic gain or practical exploitation. He concludes that these characteristics are fundamental to aesthetic mood.

Within the framework of aesthetics, the show of good moral behavior is described, among the Tongu-Ewe as beautiful or fitting. Anything short of this is seen or described as not beautiful. It is therefore, expected that a composer or user of an appellation should not use any foul language in his delivery, tease, taunt or vilify. It is however, permissible when a user uses the genre to check or condemn any act of misconduct which is a potential threat to the social order. It is also acceptable to tease, taunt and vilify when there is a joking relationship between the appellation user and the listener.

The question that readily comes to mind is how were the appellations used in the study collected? In addressing this question, the purpose of the entire study which is a study and analysis of thematic aesthetic qualities and social values of appellations was considered. This consideration was given because beauty and values are related to physical objects and human actions and behavior. Thus, the objective of the study is not merely to appreciate beauty and values for the sake of it but to see how the two elements manifest and is applied in human and communal living.

To achieve the above objectives, the selection of the appellations was also determined by their structure. It is through the analysis of the various elements of the structure of appellations such as truncation, stem and its explanation or justification, the literary features and devices, the style, tonality, imagery including communicative, interpretative and the meanings they convey that the aesthetic and values of the genres can be established and appreciated. They largely dictate how the aesthetics and values of appellations influence the conduct of the people.

The objective of the study also influenced the selection of appellations in that the people's creative sense and world view induce consideration of such issues as sources, themes, nature, forms, qualities and classification of appellations which severally and collectively create the beauty and values which the people love, enjoy and cherish. Besides, knowing and acknowledging historicity of the genres, selection was motivated by how these appellations are owned or disowned and how they are expressed through various performances. Finally, to be able to prove that appellations are not only individually and communally owned, but also to establish that they are educations medium through which the culture and acceptable standard of society are transmitted from generation to generation, the selection of the types that would throw a searchlight on them was made.

Above all, again, since appellations are individual and communal possessions and, therefore, social and linguistic assets, the nobility made up of chiefs, wealthy men, the priesthood, ex-soldiers, teachers, clan and family heads as well as individual men and women, totaling up to fifty (50) were interviewed on their etymology, definition, sources, types, forms, qualities, among others. At least, each respondent gave between two and ten appellations respectively over a three-year period. The researcher was given the opportunity to observe sessions during which a few of the genres were rendered 
orally through dialogue, on the drum and with the horn. Additionally, my third-year students of Ewe from all over the Volta Region collected twenty appellations each on the basis of the criteria described above and submitted them to the investigator. A few were also picked from Ewe textbooks. In all, the appellations cited in the study were selected from about one thousand, five hundred collections.

Appellations and their use among the Tongu-Ewe have direct moral implications. Moral or morality comes from the Latin word 'moralis' meaning the custom or way of life (Titus and Smith, 1974 p.116). This implies that morality goes with decision-making. The decisions or actions that individuals take to determine whether the decision or action taken is morally right or wrong. It means also that to have any orderly social life, there must be understanding, principles and rules of conduct. It is because morality is co-existence with life itself, moral practices and standards depends on stages of development, level of intelligence and knowledge available at the time. It implies that the character of individuals is influenced by development, intelligence and existing knowledge. The character and behavior of man is of great importance of society. AsareOpoku (1978:166) makes this assertion that a man's character is of supreme importance and it defines him as an individual in society. He points out further that God and man judge this character of man. Furthermore, to say in African societies that a person is 'good' or 'bad' has extremely profound connotations, for it summarizes the whole image or picture of the person in the context of his actions.

The main thrust of African morality is to promote good and harmonious relations between men in society. To ensure this, most of the important virtues are either couched in proverbs, other forms of folklore and in appellations with moral values in them. Appellations and proverbs, in particular, have expectations and observations of moral actions and values or act as yardsticks for judgments in times of moral lapses or good show of morality. For example, an appellation delivered appropriately during an argument or in any form of discourse is likely to settle a dispute between people or promote goodwill and friendship. Many of the genres remind people to observe positive and acceptable norms and mores of society. They are, therefore, important socio-linguistic tools for the education of the youth. In all these, conscience plays an important role. AsareOpoku (1978 p. 166) supports this assertion that moral values of West African peoples have to a large extent rest on conscience or the faculty of recognizing the distinction between right and wrong with regard to a person's own conduct. Composition, ownership and expression of appellations are directly related to the individual's conscience. It is realized then that within the socio-linguistic context, aesthetic values, beauty morality, knowledge and wisdom are inherent elements of appellations. These inherent characteristics are expressed for pleasure, participation and value judgments of an audience. The fact is that the delivery of appellations is useless if it does not involve the community and individuals. The genre is thus the product of individual minds and the collective possession of the community.

A community is a group of persons linked by interpersonal bonds who share common values, interest and goals (Gyejye 1996: 55). In other words, it refers to community as a set of relationships operating within certain boundaries. He adds at it is a locality, denotes a network of relationships. The network of relationship is characterized by conflicts and as well as mutuality and with certain qualities. He concludes that it is associated with what is referred to as communal spirit. This communal spirit is also referred to as communities, an intense community spirit, a feeling of great social solidarity, equality and togetherness.

One of the unifying and corporate forces among the Tongu-Ewe is the use of appellations. Through appellations, the people share common values, interests and goals. Within this locality, a network of social relationships is established at levels of age, status, marriage and vocation. Again, through the use of the genre, mutuality, social, solidarity and equality are attained. On the contrary, conflicts such as fights and insults are created and resolved. Through these avenues, cohesiveness and social harmony is achieved. In line with communal spirit, appellations are used among the Tongu-Ewe as media of communication and social intercourse. Besides, it is members of the communities who endorse or sanction people's ownership and withdrawal of a particular appellation which appears to dent the image of an individual, family or clan from public domain. It is also the actions or inactions of members which prepare the ground for the creation of new appellations or revision of the old ones. Above all, it is the communities that determine and preside over the use of language. Members are compelled to do so because they acknowledge the existence of common values, obligations, understandings, feelings of loyalty and commitment to the community that are expressed through the desire and willingness to advance its interests.

To achieve and sustain the command spirit, the roles of the individual then become paramount. Individuals must exercise their personal will and identity if society is to make progress. The achievements of the community depend on the exercise by its individual members of the unique talents and qualities which are assets of the entire community. This means that the individual is to identify himself with the group if he is to have meaningful life. Gyekye (1996, p.46) tells us that the respect and social standing of an individual, the influence he has on others and his personal sense of responsibility-all this is measure in terms of how much sensitivity the individual demonstrates to the needs, demands and welfare of the group.

Conversely, when the character of individuals degenerates, the capacity and quality of life of the whole community are affected resulting eventually in the decline and fall of the society. It is within the communal spirit that the use of appellations can be appreciated. As noted earlier, the individual is socially mandated to own, inherit and receive one or more appellations as a gift. He has the right to use those of his colleagues provided the laid down rules of procedure are followed. He has the copyright to compose a number of the genres at will and is expected to grasp the education of the messages that the genre renders to society. As an individual, he is entitled to enjoy the use of and participation in appellations as a member of the audience. The individual must take note of the freedom and restrictions governing the use of the genres. Appellations belonging to certain communities, families, and clans are allowed to be used occasionally during rituals but those belonging to individuals and divinities are used daily freely because of the need for constant and persistent social intercourse. In discharging these social and linguistic obligations, the entire community and individuals 
must observe the rules. The point worth stressing in this direction is that the compelling force of the genre to guide the citizenry to live up to their social responsibilities is a demonstrative category of the aesthetics and usefulness for the people.

\section{Recommendationsand Conclusion}

The objective of the research is to investigate the functional analysis of appellations among the Tongu-Ewe. The study indicates that appellations have moral values. Values are orderly social life, understanding of principles and rules of conduct. Values are also seen in this context as ideas functionality, appropriateness and qualities of appellations. The study shows the impressive functions of appealing through the analysis of their structure, form and style. It further concluded that the creator of appellation is a creator of values because appellations contribute to the ethics of the Tongu-Ewe society.

The study also influenced the selection of appellations in that the people's creative sense and world view induce consideration of such issues as sources, themes, nature, forms, qualities and classification of appellations which severally and collectively create the beauty and values which the people love, enjoy and cherish.

From the study, it was revealed that the environment has tremendous influence on the life of the Tongu-Ewe. It is, therefore, indispensable particularly in the production of appellations. In the light of this, it is suggested that the citizens and members of the society must be sensitized to embrace and support the states policy on maintaining and sustaining the culture of the people so as to preserve and sustain the composition and use of appellations.

In addition, appellations are potent forces for the resolution of conflicts in order to ensure peace and stability in the society. In line with this statement, it is useful to suggest that the mere inclusion of the genre in the Ghanaian language's curriculum is not enough. Policy makers must ensure the effective teaching and learning of not only appellations but also the other oral arts in order for them to achieve their educational objectives. Teachers and other educationist must be encouraged and supported to teach them for entertainment, communication, philosophy of traditional education and ethics. The youth, in particularly, must be encouraged to learn and appreciate the ethical and aesthetic lessons of the genre to enable them to learn to overcome the temptations that lead them to involve in acts of indiscipline, crime and shameful conducts. Finally, it is suggested that researchers should be resourced and financed to undertake research intensively and extensively in the oral arts in order to produce the future scholars of the language.

\section{References}

i. Finnegan, R. (1970). Oral literature in Africa. London: Oxford University Press.

ii. Gyekye, K. (1997).Tradition and Modernity: Philosophical reflections on the African experience, Oxford, Oxford University Press.

iii. Gyekye, K. (1996). African Cultural Values: An Introduction, Accra: Sankofa Publishing Company.

iv. Okpewho, I.(1992). African Oral Literature. Bloomington: Indiana.

v. Opoku, K. A. (1978).West African traditional religion, Accra, etc.: FEP International Private. 